\title{
ASPECTOS ESTRATÉGICOS E RELACIONAIS DAS ALIANÇAS DO TIPO JOINT-VENTURE: o caso de dois fabricantes da indústria automobilística
}

\author{
1- Marina D’Agostini* \\ Mestranda em Administração pela Universidade de Caxias do Sul (UCS), Brasil. \\ marina.dagos@gmail.com \\ http://lattes.cnpq.br/0082525481590528
}

\section{2- Rodrigo Marques de Almeida Guerra}

Mestre em Engenharia de Produção pela Universidade Federal da Paraíba (UFPB), Brasil. Doutorando em Administração pela Universidade de Caxias do Sul (UCS), Brasil.

Professor do Curso de Graduação e Especialização Lato Sensu em Administração da Universidade de Caxias do Sul (UCS), Brasil.

rmaguerra@ucs.br

http://lattes.cnpq.br/8010434422032876

\section{3- Rosa Maria Sartor}

Mestranda em Administração pela Universidade de Caxias do Sul (UCS), Brasil. rosa13092011@gmail.com

http://lattes.cnpq.br/5406552481942331

\section{4- Vilmar Antonio Gonçalves Tondolo}

Doutor em Administração pela Universidade do Vale do Rio Dos Sinos (UNISINOS), Brasil.

Professor do Programa de Pós-Graduação em Administração da Universidade de Caxias do Sul (PPGA/UCS), Brasil. vtondolo@gmail.com

http://lattes.cnpq.br/8949425307961537

\section{Editor responsável pela submissão: Edson Ronaldo Guarido Filho.}

Artigo analisado via processo de revisão duplo cego (Double-blind).

Recebido em: 21/09/2013

Aprovado em: 30/04/2014

última Alteração: 02/02/2014

* Contato Principal:Antonio Ribeiro Mendes, 2069. Bairro São José. Cep: 95032-600. Caxias do Sul - RS, Brasil. 


\section{ASPECTOS ESTRATÉGICOS E RELACIONAIS DAS ALIANÇAS DO TIPO JOINT-VENTURE: O CASO DE DOIS FABRICANTES DA INDÚSTRIA AUTOMOBILÍSTICA}

\section{RESUMO}

Este artigo tem como objetivo analisar a formação de joint-ventures de dois fabricantes da indústria automobilística, compreendendo aspectos estratégicos e relacionais destas alianças. A pesquisa caracterizou-se por ser um estudo de casos múltiplos, qualitativo e exploratório, onde foi possível realizar uma melhor compreensão das duas subsidiárias nacionais e suas respectivas joint-ventures localizadas nos Estados Unidos (EUA), Alemanha, México e Egito. A coleta dos dados foi feita por meio da observação participante e roteiro de entrevista semi-estruturado. Os dados foram analisados por meio da análise de conteúdo. Dentre os resultados, foi identificado como primordial para o sucesso da implementação deste tipo de aliança, a realização de um detalhado estudo de viabilidade que deve anteceder a formação da joint-venture, seguido de um alinhamento entre os interesses das sócias. As adaptações aos aspectos culturais aparecem como um ponto forte para a sobrevivência das joint-ventures. As informações obtidas neste estudo convergem com a teoria estudada e conduzem a novas oportunidades de pesquisas relacionadas ao tema.

Palavras-chave: Aliança estratégica. Joint-venture. Indústriaautomobilística.

\section{STRATEGIC AND RELATIONAL ASPECTS OF JOINT-VENTURE ALLIANCES: THE CASE OF TWO MANUFACTURERS OF THE AUTOMOTIVE INDUSTRY}

\section{ABSTRACT}

This article aims to analyze the formation of joint ventures formed by two manufacturers from automobile industry, understanding strategic and relational aspects of these alliances. This research is characterized by a qualitative and exploratory multiple case study, where it was possible to conduct a comparison of two subsidiary and their joint ventures located in the United States (USA), Germany, Mexico, and Egypt. The data collection was done through participant observation and semi-structured interviews. The data were analyzed using content analysis technique. Among results, it was identified as essential for the successful implementation of this type of alliance, to conduct a detailed feasibility study which must precede the formation of the joint venture, followed by an alignment between the interests of the partners. Adaptations to the cultural aspects seem as a strong point for survival of joint ventures. Information obtained in this study converges with the theory studied and lead to new research opportunities regarding to the theme.

Keywords: Strategic alliance. Joint-venture.Automobileindustry. 


\section{Introdução}

Diante do atual ambiente de negócios internacional, empresas de diversos segmentos buscam a diferenciação competitiva por meio da formação de alianças estratégicas, tendo em vista o alcance dos seus objetivos estratégicos (Hsieh, Rodrigues \&Child, 2010). No caso do setor automobilístico, a busca por novos mercados consumidores fez com que algumas empresas deste setor optassem pela formação de joint-ventures (Bernardi, 2011). Este fato ocasionou a inserção de novos produtos em mercados ainda não explorados, contribuindo para o surgimento de armadilhas (Lorange\& Ross, 1996).

Neste sentido, pode-se conceituar aliança estratégica como sendo um acordo comercial entre empresas, geralmente com objetivos comuns em um mesmo negócio, no intuito de realização de benefícios mútuos por meio de tecnologia, inovação, pesquisa e desenvolvimento (P\&D) etc., sendo necessária, para sua concepção, a formação de uma parceria (Dahab, Guimarães \& Dantas, 1992; Lewis, 1994; Gulati, 1998; Doz\&Hamel, 1998; Oliver, 1990). Por exemplo, no segmento automotivo, podem-se encontrar diversas empresas que tenham desenvolvido alianças estratégicas (Lorange\& Ross, 1996).

A alta administração tem papel central no êxito da aliança estratégica, principalmente se existir a articulação eficiente com o nível tático por meio de controles e monitoramentos, inovação tecnológica, pesquisa e desenvolvimento $(P \& D)$, quebra de paradigmas, formação de uma cultura organizacional própria para a jointventure, métricas adequadas para a aliança, gestores de conflitos etc. (Callahan\& Mackenzie, 1999).

Contudo, a existência de problemas e dificuldades para a formação de uma joint- venture é notória. Assim, alguns dos desafios apresentados pelas empresas podem ser, dentre outros: identificar as características que contribuem para a assimetria tecnológica e de poder, bem como oportunidades de ganhos (Williamson, 1996; Kumar, 2007; Peng, 2008; Faemset. al., 2012); analisar em que momento ocorre à manifestação de comportamento oportunista visando interesse próprio das partes interessadas (Williamson, 1996; Boone\&Kurtz, 2009; Hoskissonet. al., 2009; Deitzet. al., 2010; Silva \& Brito, 2013); e compreender a existência de riscos quanto ao compartilhamento de ativos e apropriação de recursos existente na joint-venture (Deitzet. al., 2010).

Uma série de pesquisas internacionais tem buscado identificar os elementos que influenciam a formação de uma joint-ventures, tais como: ambiente de inserção (Basso, 1994), intenção de formação (Lorange\& Ross, 1996), influência de participação (Hoskisson et al., 2009), aspectos culturais da aliança (Park \&Ungson, 1997), custos de transação (Chen, Peng\&Saparito, 2002), comportamento oportunista (Deitz et al., 2010), ganhos assimétricos (Hsieh, Rodrigues \&Child, 2010) e aspectos relacionais (Sutcliffe\&Zaheer, 1998). Estes elementos têm influenciado diversos autores brasileiros a compreenderem os aspectos estratégicos e relacionais que auxiliam na formação de joint-ventures.

Pesquisas de âmbito nacional investigam, de forma empírica, elementos que interferem nos aspectos estratégicos de organizações, a exemplo do estudo de Silva \& Brito (2013) que analisaram os mecanismos que contribuem para as incertezas, racionalidade limitada e especificidades dos ativos da indústria brasileira. A pesquisa realizada por Tondolo\&Puffal (2010), por sua vez, buscou compreender os antecedentes e os principais resultados de um programa de capacitação empresarial como um tipo de relação interorganizacional em empresas do segmento metal mecânico automotivo. Já o estudo de Rodrigues (1999), buscou identificar os principais aspectos relacionados a(o): i) acesso a novos mercados consumidores; ii) diversificação dos canais de distribuição; iii) inovação tecnológica em joint-ventures; iv) acesso a patentes e licenças; dentre outras.

Dentro desse contexto, o objetivo geral desta pesquisa foi analisar a formação de joint-ventures de dois fabricantes da indústria automobilística, compreendendo aspectos estratégicos e relacionais destas alianças. Para atender ao objetivo geral, foram propostos os seguintes objetivos específicos: verificar a intenção estratégica da formação da joint-venture em cada um dos fabricantes; comparar as vantagens e desvantagens da aliança estratégica, assim como os benefícios e dificuldades; analisar os aspectos culturais e relacionais envolvidos.

Os dois fabricantes da indústria automobilística escolhidos para este estudo foram a empresa Alfa, há mais de sessenta anos em atuação e líder nacional no mercado de implementos rodoviários e ferroviários, e a empresa Beta, líder nacional na fabricação de carrocerias de ônibus e atuante em diversos mercados internacionais. Estas empresas foram escolhidas por serem pioneiras na formação de alianças do tipo jointventures em seus mercados de atuação. A relevância desta pesquisa, de cunho empírico, se dá pela complexidade das alianças estratégicas e pelo papel das mesmas na plataforma brasileira de produção e consumo, conduzindo as subsidiárias nacionais à expansão de seus negócios e auxiliando os pesquisadores nacionais a explorarem os aspectos estratégicos e relacionais sob a ótica das joint-ventures com maior profundidade, pelo fato do restrito volume de publicações nacionais a respeito desta temática.

Tendo em vista uma melhor compreensão do estudo, o artigo foi desenvolvido em seis seções. Na segunda seção, realizou-se uma revisão da literatura a respeito dos principais conceitos referentes à aliança estratégica, joint-venture, benefícios e dificuldades para a formação deste tipo de aliança. Na terceira seção, buscou-se explicar a metodologia utilizada para a construção do estudo, bem como a forma de coleta de dados e posterior análise. Na quarta seção, foi realizada a caracterização do ambiente de pesquisa, descrevendo brevemente as subsidiárias nacionais Alfa e Beta e suas joint-ventures, e construído o estudo de caso propriamente dito, buscando analisar a formação da joint-venture em seus aspectos estratégicos e relacionais. 
Na quinta seção discutiram-se os resultados obtidos e na sexta seção apresentam-se as considerações finais e recomendações para estudos futuros.

\section{Referencial Teórico}

Nos anos 90, os mercados passaram a ganhar dimensões mundiais. As organizações passaram a adotar estratégias direcionadas para a atividade central da empresa (core business). As empresas passaram a adquirir suprimentos no menor valor possível e de qualquer parte do mundo. Esta estratégia visou à redução drástica do valor do produto final, buscando tornar o produto competitivo em qualquer mercado. O processo de produção passou a ser horizontalizado devido à grande especialidade das empresas e busca por empresas com características complementares e formação de parcerias especializadas (Mintzberg, Ahlstrand\&Lampel, 2000; 1980, 1990). Dessa forma, estratégia coletiva, terceirização estratégica e a própria aliança estratégica, tornaram-se, na época, novos termos na estratégia organizacional e competitiva (Mintzberg, Ahlstrand\&Lampel, 2000).

Nesse sentido, a partir dos anos 1990, as organizações, com mais frequência, passaram a estabelecer relações interorganizacionais de forma estratégica. O fortalecimento das redes de empresas contribuiu ao o adensamento das alianças estratégias. Estas foram estabelecidas entre redes de empresas (supplychain) e não mais individualmente (Chopra \&Meintl, 2001). A busca pela formação de parcerias era determinada pela cadeia de suprimentos, não sendo uma ação isolada da empresa. Nesta nova etapa, a escolha da melhor estratégia de aliança dependerá de alguns fatores, a saber: porte da empresa, nível de diferenciação do produto, grau de inovação tecnológica necessária à produção, penetração em novos mercados, entre outros. (Kotler, 2000). Desta forma, acordos de terceirização e cooperação tornaram-se cada vez mais frequentes (Chesnais, 1996), atraindo também, a atenção dos pesquisadores na área da gestão (Clegg, Hardy\&Nord, 1998).

\subsection{Alianças Estratégicas}

Define-se aliança como sendo relacionamentos entre organizações, geralmente que fazem parte de um mesmo mercado, todavia que precisam unir forças em função dos objetivos comuns (Dahab, Guimarães \& Dantas, 1992; Gulati, 1998). No entanto, a literatura acadêmica ainda não estabeleceu um consenso a respeito do conceito de aliança estratégica. Para efeito deste artigo, e a partir da definição de Gulati (1998) e Baker, Gibbons e Murphy (2002), conceitua-se aliança estratégica como sendo uma estrutura de governança baseada na união espontânea de empresas que, por meio de contrato formalizado de longo prazo, compartilham recursos, tecnologias e informações. Algumas de suas estruturas incluem a formação de join-ventures, aquisições e alienações mútuas.

A aliança estratégica também pode ser definida como uma estratégia de cooperação em que as empresas combinam alguns de seus recursos e capacitações para criar uma vantagem competitiva(Deitz et al., 2010). As estratégias cooperativas são formadas cada vez mais por empresas que também competem entre si, em um ambiente denominado de coopetição. (Hoskisson et al., 2009).

Segundo Lewis (1994), o fortalecimento da aliança estratégica está baseado em algumas atividades que geram a cooperação, que são: (i) transferência de tecnologia; (ii) divisão de custos e riscos; (iii) aumento da competitividade no mercado; (iv) realização de experiências conjuntas; (v) reduzir a exposição de investimentos; ( $v i)$ penetração do produto em novos mercados; dentre outras. De forma geral, as alianças estratégicas permitem as empresas melhor acesso a mercados e recursos, bem como, compartilhamento de recursos, em especial conhecimento (Lewis, 1994).

As ações de cooperação entre empresas, por aliança estratégica, ou outra forma de relações interorganizacionais, permitem que as empresas compartilhem atividades entre suas cadeias de valor. Os interrelacionamentos na cadeia de valor podem gerar vantagem competitiva, pelo aumento do volume de negócios, gerando barganha, e pela redução de custos gerada pelo incremento do volume. Além disso, as empresas podem estar compartilhando e explorando oportunidades que não seriam viáveis ou possíveis de forma isolada (Porter, 1990).

Vários autores classificam a tipologia de alianças estratégicas de forma distinta. Por conta desta diversidade de conceitos, ainda não foi possível encontrar um tipo de classificação que sirva como referência. Para Doz e Hamel (1998), existem quatro tipos de alianças: i) aliança estratégica; ii) aliança horizontal; iii) aliança transacional; e iv) aliança vertical. Klotzle (2002) também apresenta quatro tipos de alianças estratégicas, a saber: (i) contratos unilaterais; (ii) participação acionária minoritária; (iii) joint-ventures; e (iv) contratos bilaterais. Dos quatro tipos de possibilidades de formação de alianças estratégicas a mais utilizada por empresas multinacionais é a joint-venture.

Lorange\& Ross (1996) classificaram os tipos de aliança estratégica em uma matriz, conforme figura 1 , reunindo quatro elementos com base na alocação de recursos, no curto e longo prazo, em relação a recuperação ou retenção de recursos empregados. Os elementos pertencentes à matriz são: i) acordo provisório: recursos relativamente baixos e as empresas-mãe recuperam esses recursos rapidamente; ii) consórcio: as empresas se dispõem a investir mais recursos nas alianças, todavia os investimentos retornam rapidamente para sua origem; iii) joint-venture baseada em projeto: as empresas destinam poucos recursos 
Aspectos estratégicos e relacionais das alianças do tipo joint-venture: o caso de dois fabricantes da indústria automobilística

para a formação de uma nova entidade; e iv) joint-venture plena: as partes estão dispostas a investir considerável quantia de recursos, que permanecem na empresa nova com certo grau de liberdade de ação.

\begin{tabular}{|l|l|l|}
\hline & Alocação de Recursos \\
\hline & $\begin{array}{l}\text { Suficiente para Operações a Curto } \\
\text { Prazo }\end{array}$ & $\begin{array}{l}\text { Suficiente para Operações a } \\
\text { Longo Prazo }\end{array}$ \\
\hline Para empresas-mãe & Acordo Provisório & Consórcio \\
\hline Conserva na aliança estratégica & Joint-venture baseada em projeto. & Joint-venture plena \\
\hline
\end{tabular}

Figura 1.Aliança estratégica

Fonte: Lorange\& Ross (1996).

Devido a sua complexidade, longa duração, demanda por recursos e interação entre as sócias, as jointventures plenas, aqui tratadas simplesmente como joint-ventures, foram escolhidas como o tipo de aliança estratégica foco deste estudo.

\subsection{Joint-ventures}

A expressão joint-venture surgiu nos Estados Unidos como uma solução para a proibição de que sociedades anônimas pudessem ser sócias de sociedades de outro tipo, de responsabilidade limitada ou ilimitada e não possui equivalente em língua portuguesa (Basso, 1994). Pode-se definir joint-venture como sendo uma organização jurídica independente que representa a união entre duas ou mais empresas, de modo cooperativo, em que a sede de pelo menos um dos parceiros está localizada fora do país da operação da jointventure (Jiang, Chu \& Pan, 2011; Chung\&Beamish, 2012).

Em significativa ocorrência, a joint-venture é formada pelo fato de uma das empresas não possuir recursos suficientes para o desenvolvimento do empreendimento de forma isolada (Gulati, 1998; Kotler, 2000; Minervini, 2005), tais como conhecimento de mercado (Kogut\&Zander, 1992). Frequentemente, devem a sua existência em função da presença de oportunidades de mercado identificadas pelas partes interessadas que perceberam que não poderiam aproveitar tais oportunidades de modo independente (Rod, 2009).

As empresas normalmente preferem estabelecer joint-ventures ao invés de outros tipos de contratos de cooperação quando os riscos envolvidos são altos, pois com o compartilhamento de capital ou ações previstos neste tipo de aliança estratégica, a dissolução da parceria é difícil. A divisão de riscos, entre as empresas envolvidas, é, portanto uma das características da formação da joint-venture, assim como a obediência das normas e leis vigentes por parte das empresas junto a seus países de origem, riscos quanto à configuração do controle, comportamento oportunista, gestão de joint-ventures pós-formação (Keegan \& Green, 1999; Hsieh, Rodrigues \&Child, 2010). Pelo fato da formação possuir diversos riscos, podendo ocasionar na rescisão da parceria, o tempo de vida útil de uma joint-venture deve ser limitado, ou seja, não deve durar indefinidamente (Jiang, Chu \& Pan, 2011).

Uma joint-venture pode ser classificada quanto à participação das suas sócias em: (i) participação minoritária: menos de 50\%, (ii) participação equitativa: igual distribuição entre as sócias, e (iii) participação majoritária: mais de 50\%. Podem também serem classificadas conforme a nacionalidade das empresas-mãe: (i) nacional: quando tomam parte duas ou mais empresas da mesma nacionalidade, (ii) internacional: duas ou mais empresas-mãe são de nacionalidades diferentes. E, por fim, podem ser divididas em: (i) corporate jointventure quando há o surgimento de uma nova empresa, e (ii) non corporate joint-venture quando não há o surgimento de uma nova entidade (Basso, 1994).

Como vantagens obtidas através de joint-ventures, podem ser destacados: compartilhamento de habilidade, recursos, capital e risco; maior poder de penetração em novos mercados, economia de escala; redução de custos, transferência tecnologia entre firmas, competitividade, inserção de produtos em novos mercados, maior participação de mercado (marketshare) entre as organizações, P\&D, produção conjunta, acordos bilaterais, acesso a novos canais de distribuição, aumento do nível de cooperação e desempenho entre as empresas envolvidas, entre outros (Kotler, 2000; Kotabe\&Helsen, 2000; Das \&Teng, 2001; Lou, 2002; Inpken, 2006).

As principais dificuldades encontradas na formação de joint-ventures podem ser: alto nível de confiança entre as empresas participantes; definição dos critérios de repartição de direitos e obrigações; resolução de conflitos; critérios para transferência de tecnologia; diferenças culturais para formação; expansão da aliança; comportamento oportunista pelo parceiro local; percepção de risco do parceiro local; governança pós-formação; vida útil limitada; e estrutura de governança estática e relacional (Keegan \& Green, 1999; Kotabe\&Helsen, 2000; Baker, Gibbons\& Murphy, 2002; Hsieh, Rodrigues \&Child, 2010).

Existem alguns fatores que podem conduzir as joint-ventures ao insucesso, que são: i) concorrentes reais ou potenciais; ii) pesquisas de marketing desenvolvidas de forma confusas; iii) não cumprimento dos contratos por parte das empresas participantes; iv) joint-venture desenvolvida de forma precipitada; e v) cultura organizacional; vi) compatibilidade entre os sócios; dentre outras (Minervini, 1997; Keegan \& Green, 1999; 
Elmuti\&Kathawala, 2001). Assim, tendo em vista minimizar as falhas existentes no estágio de formação e pósformação da joint venture, é importante avaliar o desempenho da parceria por meio de avaliação de desempenho, transformando as medidas de resultado contínuo em medidas discretas de sucesso ou fracasso (Chung\&Beamish, 2012).

Portanto, alguns cuidados devem ser tomados antes da formação da joint-venture, a saber: i) evitar estabelecer joint-venture com empresas que queiram apenas o controle ou ruptura em caso de problema; ii) a joint-venture não deve limitar-se geograficamente e/ou tecnologicamente; iii) a cultura da joint-venture deve ser própria (não se confundindo com as organizações participantes); iv) acesso as decisões da alta administração de forma facilitada; e v) evitar relações de parcerias com empresas centralizadoras e sem experiência (Jeannet\&Hennessey, 1998).

Além das dificuldades para formação da joint-venture (já mencionadas), podem-se destacar, também, alguns elementos importantes para a compreensão da formação da aliança estratégica, que são:

- Intenção de formação: definição dos elementos essenciais para a formação da aliança estratégica entre as empresas (como por exemplo: nível de confiança entre os sócios; fator cultural; riscos e incertezas; nível de controle etc.). (Lorange\& Ross, 1996; Koza\& Lewin, 1998).

- Contexto de inserção: envolve a qualificação das partes envolvidas, intenção dos sócios, transferência de tecnologia, venda de produtos/serviços, idioma, constituição da sociedade etc. (Basso, 1994).

- Influência de participação: em regra, a formação da joint-venture é proposta com base no interesse econômico-financeiro dos sócios envolvidos no negócio, recursos e capacidades dos sócios, formação de políticas de regulamentação, envolvimento tecnológicos etc. (Richards \&lndro, 2006; Hoskisson et al., 2009).

- Comportamento oportunista: refere-se a como as partes interessadas da joint-venture agem em benefício próprio em decorrência dos gaps (por exemplo, lacunas contratuais e compartilhamento de recursos e tecnologia), em detrimento da atuação da empresa parceira. Muitas vezes, o comportamento oportunista pode gerar atos destrutivos na parceria (Williamson, 1996; Boone\&Kurtz, 2009; Hoskisson et al., 2009; Deitz et al., 2010). Algumas das causas que acarretam o comportamento oportunista podem ser: lacunas existentes nos contratos formais e exagero nos custos visando renegociar condições que beneficiem apenas uma das partes interessadas e situação sociocultural superior ao do parceiro (Silva \& Brito, 2013; Chen, Peng\&Saparito, 2002). A ameaça oportunista e a rivalidade na parceria podem gerar fortes indícios para a dissolução de joint-ventures (Park \&Ungson, 1997).

- Ganhos assimétricos: diz respeito às diferenças quanto à obtenção de riqueza em joint-ventures. 0 alcance de ganhos assimétricos pode ser oriundo das divergências tecnológicas, elementos contratuais, custo transacional e de poder entre as empresas envolvidas (Nielsen, 2009; Kumar, 2007; Faems et al., 2012) possibilitando o surgimento de riscos quanto a: incapacidade ou falta de vontade de perseguir os objetivos acordados; compartilhamento de ativos; e apropriação de recursos da joint-venture (Deitz et al., 2010; Hsieh, Rodrigues \&Child, 2010).

- Custos de transação: interfere negativamente na adoção de estratégias para a formação de jointventures, comprometendo o desempenho e sobrevivência da aliança (Jones, Hesterly\&Borgatti, 1997). Os custos de transação podem ser minimizados a partir do aumento da relação de confiança, conhecimento dos recursos utilizados e know-kow (Gulati, Nohrian\&Zaheer, 2000). Caso contrário, se o custo de transação for elevado, este pode ocasionar comportamento oportunista entre as partes envolvidas (Chen, Peng\&Saparito, 2002). Tsang (2000) afirma que há relação entre os custos de transação, falhas de mercados, insumos intermediários e especificação dos ativos, proporcionando elevada incerteza quanto ao desempenho da aliança.

- Aspectos culturais: estudo desenvolvido em 186 joint-ventures japonesas revela que os aspectos culturais, em regra, não interferem na dissolução da aliança estratégica (Park \&Ungson, 1997). Entretanto, pesquisa desenvolvida em PME de cinco países indica que a cultura nacional influencia diretamente na formação de joint-ventures, principalmente quanto as incertezas tecnológicas e dependência de recursos (Steensma et al., 1999).

- Aspectos relacionais: a obtenção de sucesso na formação de uma aliança depende da geração de inovação, grau de cooperação, criatividade, troca de informações, formação de equipes e estrutura relacional das partes envolvidas (Van de Ven, Angle\& Poole, 1989). Desta forma, a confiança contribui para a cooperação, reduzindo o risco relacional (Das \&Teng, 2001). Os autores indicam dois aspectos que geram dúvida na formação da aliança: incerteza relacional e tecnológica (Das \&Teng, 1996). A incerteza tecnológica contribui para o aumento da incerteza relacional inerente às relações interfirmas (Sutcliffe\&Zaheer, 1998), podendo gerar uma ampla fiscalização, contratos com cláusulas de contingência, renegociações, altos custos de transação e parcerias vulneráveis (Pearce, 1997). 


\subsection{Aspectos Estratégicos e Relacionais para Formação de Joint-ventures}

Peng e Delios (2006) afirmam que o escopo do produto e o escopo geográfico são determinantes para a formação de alianças estratégicas entre grupos de empresas e conglomerados. Dependendo do tipo de aliança estratégica estabelecida, a localização geográfica (Peng\&Delios, 2006), nível de cooperação (Gulati 1995; Poppo e Zenger, 2002; Lou, 2002), formas de controles (Li et al., 2010), diferença cultural (Steensma et al., 1999), aspectos relacionais (Das \&Teng, 1996) e custos de transação (Jones, Hesterly\&Borgatti, 1997) podem contribuir para a formação de joint-ventures.

Park \&Ungson (1997) afirmam que a formação de uma joint-venture entre um parceiro americano e japonês está mais propensa a um rompimento do que se a mesma fosse realizada entre países asiáticos. Este fato pode ter relação com o aspecto cultural entre as partes envolvidas (Park \&Ungson, 1997), bem como a recente participação neste tipo de aliança por países orientais (Peng, 2000, 2002). Para Peng (2008), o desenvolvimento da estratégia entre joint-ventures pode ser determinante para o sucesso da mesma. Assim, as empresas envolvidas devem realizar um estudo mais denso sobre a diversificação de produtos, distanciamento geográfico, cultura dos países e amplitude das empresas antes de realizarem qualquer tipo de estratégia de longo prazo (Peng\&Delios, 2006; Steensma et al., 1999; Peng, 2008).

Percebe-se que o intuito da formação de joint-ventures deve-se ao acesso das mesmas a novos mercados consumidores, canais de distribuição diferenciados, inovação tecnológica, acesso a patentes e licenças, com o intuito de conquistarem vantagem competitiva em relação às empresas concorrentes (Rodrigues, 1999). O estabelecimento de estratégias competitivas, na formação de joint-ventures, tem a finalidade de gerar repartição de investimentos, oferta de novos serviços, economia de escala, desenvolvimento de novos produtos, permitindo maior relação interorganizacional entre as partes (Gulati, 1995, 1998; Rodrigues, 1999).

Entende-se por relacionamentos interorganizacionais qualquer forma de contato cooperativo estabelecido entre duas ou mais empresas independentes (Combs \&Ketchen, 1999), de segmentos similares ou não, com a finalidade de estabelecimento de parcerias e/ou novas formas de relacionamento (Oliver \&Ebers, 1998) que proporcione oportunidade competitiva para as organizações envolvidas (Oliver, 1990), por meio de diversas abordagens teóricas, como por exemplo: dependência de recursos, teoria dos custos de transação e estratégias organizacionais (Verschoore\&Balestrin, 2008).

Portanto, o relacionamento interorganizacional passou a ser utilizado como forma de desenvolvimento e sobrevivência das organizações, tendo em vista o aumento da competição interfirmas (Tondolo\&Puffal, 2010). Este fato contribui para a formação de joint-ventures em organizações de diferentes culturas e estágios de desenvolvimento, principalmente quando uma das empresas envolvidas tem a origem em um país emergente (Rodrigues, 1999).

\section{Metodologia da Pesquisa}

O presente trabalho tem como objetivo geral analisar a formação de joint-ventures de dois fabricantes da indústria automobilística, compreendendo aspectos estratégicos e relacionais destas alianças. Esta pesquisa caracteriza-se como sendo um estudo de casos múltiplos, exploratório e de natureza qualitativa. De acordo com Yin (2005), entende-se por estudo de múltiplos casos àquele que envolve mais de uma unidade de análise. Este estudo considerou múltiplos casos pela necessidade de análise e maior compreensão das duas empresas multinacionais brasileiras e de suas joint-venture com EUA, Alemanha, México e Egito.

As unidades dessas empresas, foco deste estudo, terão suas identidades preservadas por questões estratégicas, sendo denominadas por Alfa e Beta as subsidiárias nacionais, por Delta e Teta as joint-ventures formadas pela subsidiária Alfa e por Gama e Ômega as joint-ventures formadas pela subsidiária Beta. As empresas Alfa e Beta foram escolhidas por serem referências na indústria automobilística nacional e por terem a prática estratégica de estabelecer joint-ventures para expansão de seus negócios no Brasil ou no exterior.

Quanto aos fins, esta pesquisa classifica-se como sendo qualitativa e exploratória. O estudo exploratório tem o objetivo de contribuir para a familiaridade dos pesquisadores a respeito do assunto investigado (Vergara, 2006). O estudo qualitativo diz respeito à finalidade de entender, com maior profundidade, a realidade estudada, sem a necessidade de análise estatística, utilizando uma seleção de amostras pequenas e não representativa (Flick, 2009). O instrumento de coleta de dados utilizado para a realização deste estudo foi o roteiro de entrevistas semi-estruturadas (Apêndice A).

O objetivo do roteiro semi-estruturado é fazer com que o pesquisador conduza a entrevista dentro de um contexto similar ao de uma conversa informal, obtendo respostas do informante quanto às questões solicitadas (Flick, 2009). Para a realização da análise dos dados foi utilizada a análise de conteúdo que pode ser definida como sendo uma técnica utilizada para o tratamento de dados, com a finalidade de identificar o que está sendo abordado sobre determinado tema (Bardin, 2004).

O roteiro de entrevistas foi formado por 10 questões abertas, buscando abordar os tópicos relacionados aos objetivos específicos do trabalho, com base nos seguintes autores: i) intenção da formação (Lorange\& Ross, 1996; Koza\& Lewin, 1998); ii) contexto de inserção (Basso, 1994), iii) vantagens e desvantagens da aliança estratégica (Kotabe\&Helsen, 2000; Das \&Teng, 2001; Inpken, 2006; Elmuti\&Kathawala, 2001; Keegan \& Green, 
1999); e iv) influência de participação (Richards \&lndro, 2006; Hoskisson et al., 2009). Os mesmos tópicos serviram como referência para a categorização da análise de conteúdo (Gibbs, 2009).

Em se tratando das joint-ventures da subsidiária Alfa, a entrevista referente à joint-venture Delta foi realizada com o ex-gerente da planta (gestor A) que participou da formação da joint-venture, todavia não atuando mais na organização e a entrevista da empresa Teta foi realizada com o gerente executivo da planta (gestor B). Quanto às joint-ventures da subsidiária Beta, as entrevistas das empresas Gama e Ômega foram realizadas com o gerente executivo de novos negócios da empresa Beta (gestor C), o qual participou de ambos os processos de formação das joint-ventures.

As entrevistas foram realizadas nos meses de janeiro e fevereiro de 2013, com duração de cerca de 4 horas cada uma e o critério utilizado para escolha dos profissionais entrevistados baseou-se na experiência dos mesmos na formação das joint-ventures. O gestor A e o gestor B acompanharam a formação de outras duas joint-ventures da subsidiária Alfa antes de liderarem a formação das joint-ventures Delta e Teta, respectivamente. O gestor $C$, pela sua longa experiência como gerente executivo de novos negócios na empresa Beta, acompanhou a formação da maior parte das dez joint-ventures subsidiadas por Beta.

Outro método utilizado para obtenção de dados foi a observação participante, pelo fato da vivência dos pesquisadores durante a formação das joint-ventures pesquisadas. A pesquisa participante ocorre a partir da interação entre pesquisadores e membros das situações investigadas (Richardson, 1999), assim como pelo fácil acesso às empresas investigadas e aos entrevistados (Flick, 2009).

\section{Análise dos Dados}

Nesta seção serão relatadas as informações obtidas com as entrevistas e por meio de pesquisa documental em cada uma das joint-ventures em questão.

\subsection{Ambiente de Pesquisa}

Para melhor entendimento do estudo, serão descritas nesta seção, as empresas envolvidas na pesquisa. Conforme informado na seção anterior, todas as empresas terão nomes fictícios com a finalidade de preservar a identidade de cada uma delas por motivos estratégicos.

\subsubsection{Caracterização da subsidiária nacional Alfa e suas joint-ventures Delta e Teta}

A empresa subsidiária nacional Alfa é uma empresa de capital aberto que está há sessenta anos no mercado, fabricando diversos tipos de implementos rodoviários e ferroviários de carga: semirreboques, reboques e carrocerias, graneleiros, carga seca, tanques, silos, frigoríficos, canavieiros, florestais, siders, furgões, vagões de carga em geral. Seu número de funcionários ultrapassa 5.000, trabalhando em três turnos e já conta com 300.000 unidades fabricadas, o que evidencia sua representatividade na expansão do transporte de cargas no país. Possui uma sólida rede de distribuidores presente em mais de setenta pontos no Brasil e sua marca está presente em mais de setenta países. Sua vantagem competitiva estratégica é a diversidade de seus produtos, por atuar em mais mercados que seus concorrentes e a qualidade de seus produtos, pois é líder de mercado mesmo apresentando preços maiores que os produtos da concorrência.

Com sua expansão e busca constante por novas tecnologias, detectou as lacunas dentro do mercado fornecedor de peças para implementos rodoviários no Brasil e formou joint-ventures com empresas estrangeiras que detinham know-how específico destes produtos-chave, para atendê-los e também atender as necessidades do mercado brasileiro.

A Delta, joint-venture da subsidiária Alfa, iniciou seu negócio há mais de meio século, como um setor fabril da sua subsidiária. Este setor fabril, especialista na produção de sistemas de suspensões para veículos comerciais, foi emancipado da Empresa Alfa em 1997, tornando-se uma empresa própria, localizada junto à empresa-mãe, porém agora não produzindo exclusivamente para a mesma. Em 2002, a Delta, tornou-se uma joint-venture entre a Empresa Alfa e uma renomada empresa americana do setor de autopeças e, no ano seguinte, ganhou uma nova sede com área total de cerca de $69.000 \mathrm{~m}^{2}$ e capacidade produtiva mensal de 300.000 peças entre sistemas de suspensões, eixos e componentes.

A Delta trabalha em três turnos (24h) e conta atualmente com um quadro de cerca de 1.650 funcionários, divididos entre atividades produtivas, atividades de apoio e atividades administrativas. A empresa é líder de mercado em todos os segmentos em que atua, sendo eles o mercado nacional e os países da América Latina. Por questões contratuais, não pode atender diretamente os mercados nos quais sua sócia tem atuação.

A Teta, outra joint-venture da subsidiária Alfa, foi criada no ano de 1995, já como uma joint-venture entre a Empresa Alfa e uma empresa alemã, líder do mercado internacional em conexões para veículos articulados. Em 1996 sua planta industrial foi inaugurada, tendo $15.000 \mathrm{~m}^{2}$ de área total e $7.000 \mathrm{~m}^{2}$ de área construída. Conta com cerca de 350 funcionários na produção, áreas de apoio e áreas administrativas, divididos em três turnos de trabalho. 
A Teta produz acoplamentos e sistemas para veículos comerciais e é líder no mercado nacional em todos seus segmentos de atuação. Seus principais clientes são: montadoras de veículos, implementadoras rodoviárias e montadoras de máquinas agrícolas. Em relação ao mercado externo, a Teta atende a toda América do Sul, sendo que as negociações com outros países dependem sempre das demais plantas da sócia alemã.

\subsubsection{Caracterização da subsidiária nacional Beta e suas joint-ventures Gama e Ômega}

A Empresa Beta é uma empresa brasileira de capital privado que atua há mais de sessenta anos no segmento automotivo de fabricação de carrocerias de ônibus: rodoviários, intermunicipais, urbanos, ônibus de pequeno porte e micros. É a maior do país em sua categoria, liderando o mercado. Além da sede brasileira, possui dez fábricas espalhadas pela América do Sul, América do Norte e Ásia, contando com mais de 18.000 colaboradores.

A estratégia da empresa Beta baseia-se na vantagem competitiva da diferenciação, entendida como a capacidade da empresa atender às solicitações específicas dos clientes na fabricação dos seus produtos. A produção é totalmente customizada, sendo cada produto uma combinação diferente e, dependendo da solicitação do cliente ou inovação prospectada pela engenharia, os novos conceitos de produtos vão sendo incorporados à linha normal de produção.

Por definição estratégica, a tecnologia de produto é desenvolvida internamente e incorporada aos seus produtos, tanto no Brasil quanto no exterior. Esta capacidade de inovação aliada ao projeto e produção interna dos componentes estratégicos, proporciona a esta empresa um diferencial competitivo a nível mundial e faz da empresa Beta uma das empresas mais internacionalizadas do Brasil. O programa de internacionalização, implementado a partir da metade da década de 90, teve como principal objetivo a consolidação da sua marca como um dos líderes mundiais neste segmente de mercado.

A Gama, joint-venture da subsidiária nacional Beta, sediada no México, também atua no segmento automotivo e tornou-se uma joint-venture em 2000, tendo como subsidiárias a empresa Beta e uma renomada empresa Alemã, fornecedora de um dos mais importantes componentes do produto final, o chassi. A sede da empresa tem área total de $547.625 \mathrm{~m}^{2}$, com $42.209 \mathrm{~m}^{2}$ de área construída e produção total de 1570 unidades no ano de 2012.

A Gama trabalha em apenas um turno (8h) e conta atualmente com um quadro de 652 funcionários, divididos entre atividades produtivas, atividades de apoio e atividades administrativas. Os funcionários da jointventure convivem diretamente com os funcionários da Empresa alemã, compartilhando inclusive o mesmo refeitório, por exemplo. A linha de montagem do produto final da joint-venture convive lado a lado com a linha de montagem do chassi da empresa alemã.

A Ômega, outra joint-venture da subsidiária nacional Beta, sediada no Egito, também atua no segmento automotivo e tornou-se uma joint-venture em 2008, tendo como subsidiárias a Empresa Beta e um grupo Egípcio líder no mercado automotivo de pequeno e grande porte e que atua em toda a cadeia de valor

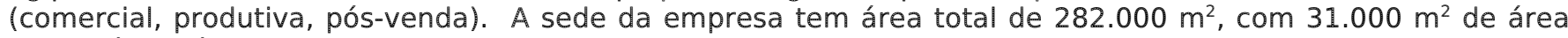
construída próximo ao canal de Suez.

A joint-venture Ômega conta atualmente com um quadro de 498 funcionários, divididos entre atividades produtivas, atividades de apoio e atividades administrativas e sua produção total foi de 510 unidades no ano de 2012.

\subsection{Joint-ventures da Empresa Alfa}

\subsubsection{A empresa Delta}

A empresa Alfa, sem deter conhecimento especializado sobre sistemas de suspensões, adquiria parte destes de subcontratados e montava em seus veículos comerciais. Já possuía uma joint-venture há cerca de dez anos com uma empresa americana para produção de sistemas de freios para veículos comerciais e, esta mesma empresa apresentou intenções de uma nova sociedade, focada em sistemas de suspensões.

A empresa americana tinha como objetivo penetrar no mercado brasileiro com maior intensidade, uma vez que vislumbrou grandes oportunidades aqui com a instalação de importantes montadoras de veículos comerciais e nenhum concorrente expressivo neste setor. A empresa Alfa, por sua vez, vislumbrou a oportunidade de adquirir know-how e tecnologias específicas deste segmento, podendo atender melhor seu processo interno e ganhar o mercado nacional. Com interesses convergentes, a parceria foi selada em 2002, sendo que a participação das sócias ficou equitativa.

Conforme relatado pelo gestor $\mathrm{A}$, foi decidido em consenso que a sócia americana ficaria responsável pelas áreas de engenharia e comercial e que a empresa Alfa ficaria com as áreas administrativas, área de produção e de apoio: "a responsabilidade das sócias sobre estas áreas reside em designar um gerente executivo para assumi-las, sempre com o aceite da outra parte e, por opção das sócias, os indicados foram brasileiros". O gestor A afirmou ainda que este é um dos fatores que explica o fato de não haver problemas oriundos de diferenças culturais entre as sócias e, mesmo que as decisões estratégicas da empresa Delta sejam 
decidas sempre em consenso, a maneira de gerenciar os processos da mesma muito se assemelha ao de sua empresa-mãe brasileira.

Entre as vantagens obtidas na joint-venture que foram citadas na entrevista, destaca-se principalmente o conhecimento de projeto e tecnologia de sistemas de suspensões. Outras vantagens consequentes destas é a conquista da liderança do mercado nacional, aumento da lucratividade, crescimento da empresa, fidelização de clientes, confiabilidade, oportunidade de investir em outros produtos do mesmo segmento. Como desvantagem tem-se as restrições de exportação que dependem da autorização da sócia americana e estão atualmente limitadas aos países do Mercosul devido as vantagens comercias e burocráticas.

O segmento de mercado em que atua a empresa Delta sempre foi altamente competitivo, com diversas empresas atuando diretamente no mercado nacional e Mercosul, mas nenhuma delas detendo uma parcela significativa do mercado. Com o crescimento da Delta e a expansão de seus clientes ela é hoje líder de mercado, detendo cerca de $60 \%$ do mesmo. Na visão do gestor A, a formação da joint-venture foi positiva e ambas as sócias estão muito satisfeitas com o resultado alcançado, que não seria tão bem sucedido em curto prazo sem a formação desta aliança estratégica. Esta joint-venture foi a terceira experiência de sucesso da empresa Alfa com empresas estrangeiras, o que deixa os caminhos abertos para novas alianças como estas no futuro.

\subsubsection{A empresa Teta}

A empresa Alfa participava de uma feira do setor automotivo em Milão, no ano de 1994, quando a empresa alemã, que também estava participando desta mesma feira fez contato com o diretor expondo seu interesse no mercado brasileiro. Na sequência, uma carta de intenções foi enviada pela empresa alemã para a empresa Alfa e iniciou-se um estudo de viabilidade, que foi inteiramente acompanhado pelo gestor $\mathrm{B}$ e se prolongou por cerca de seis meses, até o aceite e assinatura do contrato da joint-venture Teta, em agosto de 1995.

Conforme o gestor B, o contrato estava focado em cinco produtos do sistema de acoplamento de veículos comerciais e o carro chefe destes produtos era fornecido à empresa Alfa pela maior concorrente da empresa alemã. Até aquele momento, a empresa alemã tinha custos altos para enviar os produtos ao Brasil, o que não deixava seu valor de venda competitivo para ganhar mercado e, assim, a parceria com Alfa auxiliaria nesta questão e, além disso, Alfa já era uma empresa de renome nacional, o que também facilitaria a aceitação dos produtos aqui. A empresa Alfa, por sua vez, percebeu a oportunidade de adquirir a técnica e as tecnologias deste novo negócio, reduzir seu custo de aquisição destas peças e ainda poder fornecer estes produtos para o mercado em expansão que já sinalizava a necessidade de fornecedores mais competitivos neste segmento.

A joint-venture formada não é equitativa em relação a participação das sócias, sendo $51 \%$ pertencente à Alfa e $49 \%$ pertencentes à empresa alemã. Estes 2\% garantiriam que, em caso de conflitos de opinião, a decisão final seria de direito da empresa Alfa, mas de acordo com o gestor B, estes $2 \%$ nunca precisaram ser utilizados, pois sempre houve consenso das sócias nas decisões importantes. Pelo contrato da joint-venture, existe um gerente executivo decidido em comum acordo entre as sócias e abaixo dele um gerente comercial indicado pela empresa Alfa e um gerente industrial indicado pela empresa alemã. Sendo assim, a produção, engenharia e apoio ficam sob gerência da sócia alemã, enquanto as partes comercial, administrativa e financeira ficam sob gerência da sócia brasileira.

As vantagens da joint-venture, na opinião do entrevistado, podem ser comprovadas pelos resultados atingidos pela empresa Teta desde o inicio de seu funcionamento que atualmente, em se tratando de sistemas de acoplamento, detém $90 \%$ do mercado. A expansão da Teta no mercado nacional e latino acabou por tirar o espaço das concorrentes, as quais que hoje representam uma parcela pequena do mercado. A desvantagem da joint-venture, exposta pelo entrevistado, reside nas restrições mercadológicas impostas pela sócia alemã, na qual a Teta deve atender apenas a América Latina, pois nos demais países é mais vantajoso que outras plantas da sócia alemã façam as negociações e fornecimento. As diferenças culturais entre Brasil e Alemanha são muitas, mas são vistas como positivas pelo gerente executivo da empresa que afirma que a sócia alemã exige da Teta muita transparência, disciplina e organização nos seus negócios.

$\mathrm{Na}$ visão do gestor B, apoiado pelos resultados positivos da empresa, a joint-venture Delta é “uma parceria bem sucedida, onde ambas as partes somaram o que possuíam de melhor e onde o respeito mútuo entre as sócias contribuiu para a formação de um ambiente harmonioso de trabalho". Não se planeja novas joint-venture a partir da empresa Teta até o momento, mas devido ao sucesso atingido pela experiência desta aliança, não se descarta as possibilidades de formação de novas parceiras.

\subsection{Joint-ventures da Empresa Beta}

A Empresa Beta concentrava suas operações no mercado interno e suas exportações iniciais atendiam clientes estrangeiros de maneira esporádica. Com a estabilização do mercado brasileiro, sem perspectiva de crescimento significativo, a empresa direcionou esforços na comercialização de seus produtos no exterior. 
Nas décadas de 70 e 80, a empresa abriu escritórios e representações em importantes mercados da América Latina, África, Oriente Médio e Europa. Durante a década de 90, visando ampliar seus negócios, a empresa adotou a estratégia de abertura de novas unidades de montagem e finalização dos produtos fornecidos pela controladora, exportando produtos manufaturados de diferentes formas (montados, parcialmente montados e totalmente desmontados). Com o aumento das vendas, o contínuo treinamento de mão-de-obra e algum desenvolvimento de fornecedores locais, a empresa Beta gradativamente conquistou esses novos mercados.

A situação econômica nacional a partir de 2003 impeliu a empresa a mudar sua estratégia de negócios no exterior. Desta forma, intensificando a mão de obra e itens de fornecimento locais para reduzir custos de produção e ser competitiva internacionalmente, não precisando mais exportar altos volumes de manufaturados do Brasil, uma vez que nossa moeda estava com câmbio favorável. Para tanto, surgiu a necessidade de desenvolver parcerias e reforçar as já existentes com empresas locais, cabendo à empresa brasileira as atividades de desenvolvimento de produtos e tecnologia de manufatura e aos parceiros locais, as instalações fabris, rede comercial e atividades financeiras.

\subsubsection{Empresa Gama}

A empresa Beta estabeleceu-se no México em 1999 e em 2000 recebeu uma proposta de uma empresa alemã, fornecedora de um dos seus principais insumos, para formação de uma aliança. A empresa Beta foi a primeira joint-venture a ser formada no exterior, neste tipo de negócio, e serviu de modelo para as que se seguiram. A proposta desta fusão foi da sócia brasileira deter $74 \%$ da joint-venture enquanto a sócia alemã participaria com os demais $26 \%$.

As atividades de comercialização, marketing, distribuição dos produtos prontos, pós-vendas e serviços de peças sobressalentes são realizadas pela sócia alemã que repassa as demandas de produção para a Gama. À sócia brasileira coube dispor de toda a tecnologia e experiência em processos no ramo automotivo, mas apesar disso, a empresa Beta ainda é muito dependente dos insumos exportados da controladora brasileira. Pela sociedade majoritária da empresa Beta, ficou decidido em contrato que a empresa Gama seria gerenciada em sua totalidade pela empresa Beta.

Atualmente, conforme o gestor $C$, as linhas de montagem de ambas as empresas sócias convivem harmonicamente lado a lado, onde o produto final de uma é o principal insumo e dá início ao processo da outra, tendo como peculiaridade a exclusividade da marca deste importante insumo. Esta planta no México atende ao mercado comum NAFTA.

Em relação às intenções de formação da joint-venture, o gestor C relata que a sócia brasileira percebeu a oportunidade de ter um fornecedor estratégico como parceiro e tornar-se competitivo naquele mercado, tentando expandir suas vendas para o NAFTA (México, Estados Unidos e Canadá) enquanto a sócia alemã vislumbrou a chance de adquirir tecnologia e conhecimento para agregar valor ao seu produto, integrando-o ao produto final.

As empresas trabalham em sinergia, mas encontram algumas dificuldades relacionadas às diferenças culturais entre Brasil e Alemanha e as formas de atuação e gestão, devido à sócia brasileira ser mais informal em seus métodos enquanto a sócia alemã é extremamente formal. Para amenizar estas diferenças culturais entre as sócias, trabalhou-se muito no desenvolvimento de confiança entre as partes, cada uma respeitando o seu modo de atuação. Cabe destacar ainda, que as dificuldades culturais encontradas sempre foram entre os sócios brasileiro e alemão, com o México não houve nenhum tipo de barreira cultural significativa (Gestor C).

As restrições mercadológicas, impostas em contrato, regem que a empresa Gama pode fornecer ao NAFTA, Cuba e Caribe e há alguns campos de atuação restritos, no mercado interno e externo, devido ao insumo principal ser exclusividade da sócia alemã, e alguns clientes optarem por outros concorrentes de mercado.

Com a formação desta forte aliança, alguns concorrentes brasileiros acabaram por copiar o modelo, estabelecendo-se no mercado mexicano para tentar competir e, os concorrentes locais criaram novos produtos para competir em segmentos não priorizados pela joint-venture.

A Gama é considerada pelo gestor C, uma joint-venture de sucesso, pois a expansão e reconhecimento da marca foram muito fortes e, segundo ele, este mesmo êxito não teria sido atingido sem a formação da aliança que gerou um pós-vendas mais rentável e todo o know-how para atender o exigente mercado NAFTA e que serviu e ainda serve de modelo a ser replicado para novos negócios.

\subsubsection{Empresa ômega}

A joint-venture Ômega iniciou sua pré-operação em 2008 e foi implantada definitivamente em Suez no Egito em 2009, juntamente com um Grupo Egípcio, líder no segmento automotivo, que possui a participação no capital de $51 \%$ e a empresa Beta $49 \%$. O contrato da joint-venture tem validade inicial de 10 anos e prevê igualdade de participação na gestão e nas decisões da empresa, apesar do Grupo Egípcio ser majoritário. 
A Empresa Beta adquiriu a etapa de fabricação na cadeia de suprimento e entra com toda a expertise em processos no ramo automotivo, enquanto a empresa egípcia entra com a representação e fornecimento do insumo principal, para as vendas no mercado interno, e com o conhecimento e renome no mercado local. Conforme explicado pelo gestor C, o governo Egípcio estimula o investimento externo no país, sendo que as empresas estrangeiras gozam de uma série de incentivos fiscais, o que facilitou a formação da Ômega. Por outro lado, faz a proteção da economia nacional com elevadas alíquotas de importação aplicadas a produtos que concorram com a produção doméstica e ameacem as respectivas indústrias do país.

Os incentivos governamentais, oportunidade de ter um parceiro local já bem influente no mercado, a mão-de-obra competitiva e de baixo custo, facilidades logísticas através do Canal de Suez, apoio de um fornecedor local forte e um mercado em amplo crescimento foram os principais fatores que motivaram a empresa Beta a aceitar a aliança com o grupo egípcio, segundo o entrevistado. O grau de influência do país junto a conglomerados econômicos como COMESA, MAGREC e MENA e a presença no mercado do Oriente Médio, Egito e Norte da África e Leste Europeu impulsionaram ainda mais esta aliança.

Ainda na opinião do gestor $\mathrm{C}$, os ganhos desta joint-venture saíram como planejado: conquista de mercado, aumento das fronteiras de fornecimento, desenvolvimento de uma nova família de produtos e implantação dos sistemas e das melhores práticas da sócia brasileira e as dificuldades consistiram basicamente em aspectos culturais: religião muito austera, informações informais e que devem ser sempre confirmadas, legislações mal estruturadas ou inexistentes e órgãos burocráticos morosos pela falta de experiências do mundo industrial e tecnologias desatualizadas.

O idioma não afetou as relações, uma vez que a língua inglesa é bastante difundida por lá. Prima-se sempre pelo respeito e bom convívio com a cultura local, principalmente com os fatores religiosos: construiu-se uma mesquita na fábrica e os horários de orações são negociados entre as partes. Fornece-se também alimentação adequada ao local e o transporte dos funcionários com opção para lavagem de mãos e pés.

Esta aliança comprovou para o gestor C que "o sucesso pode ser obtido numa parceria empresarial mesmo trabalhando-se com culturas tão distintas entre si e incentivou a empresa Beta a estudar a ampliação de seu negócio para novos mercados". A empresa Beta possui também uma aliança deste tipo com um grupo chinês, que foi estimulada principalmente pelos bons resultados da Ômega.

Existem restrições mercadológicas previstas no contrato da joint-venture, o que é muito comum neste tipo de contratos conforme o interesse das sócias. Em relação ao comportamento da concorrência, após a instalação da empresa Ômega, os de pequeno porte perderam mercado e cessaram suas atividades enquanto que um fornecedor local mais estruturado fez uma aliança semelhante com uma empresa alemã para tornar-se competitivo. Concorrentes brasileiros ainda não se aventuraram no mercado egípcio.

A Ômega é considerada pelo gestor C, uma experiência de joint-venture bem sucedida, com presença forte da marca neste mercado e que contribuiu consideravelmente para os lucros da empresa Beta até 2010: “tal êxito não teria sido obtido sem a formação da aliança, pois seria difícil a aceitação no país sem um sócio local."

A partir de 2011, a revolução da irmandade muçulmana, uma variável incontrolável, causou a queda do governo e um abalo político econômico em todos os segmentos e gerou um aguardo estratégico para entender os próximos movimentos do mercado e política do país. A Empresa Ômega com queda de quase metade da sua produção mensal teve que reestudar o cenário, adequar os produtos e processos, ajustar o quadro funcional, observar o comportamento e movimento dos mercados interno e internacional, antever oportunidades e ganhos futuros, lidar cautelosamente com esta situação, até que a estabilidade interna retorne aos padrões normais.

\section{Análise e Discussão dos Casos}

No desenvolvimento deste estudo foi possível identificar dois objetivos principais distintos entre as jointventures formadas pela empresa Alfa e as joint-ventures formadas pela empresa Beta: Alfa buscava técnica e tecnologias para ampliar sua gama de produtos e sua participação no mercado nacional e Beta, por sua vez, buscava fornecer a técnica e a tecnologia para seus parceiros a fim de expandir sua participação no mercado externo.

Ambas as joint-ventures estudadas podem ser classificadas como joint-ventures plenas, onde ambas as sócias investiram significativamente nesta aliança e com intenção de longa duração (Lorange\& Ross, 1996). A classificação de cada uma das joint-ventures, nas demais categorias expostas no referencial teórico (Basso, 1994), segue na Figura 2.

Observa-se uma tendência de que as joint-ventures sejam internacionais e do tipo corporate com a formação de uma nova indústria a partir das empresas-mãe. Isso pode ser explicado pelos objetivos das sócias na formação destas alianças, buscando ampliar sua participação no mercado externo (Rod, 2009), ou buscando tecnologias e conhecimentos ainda não comumente disseminados nacionalmente (Gulati, 1998; Kotler, 2000; Minervini, 2005; Kogut\&Zander, 1992). Em relação à participação de cada uma das sócias, percebeu-se que não há consequências marcantes relacionadas a isto no modo de gerir as joint-ventures, conforme pode ser percebido nas entrevistas, as decisões relevantes são consensadas entre as partes, o que mantém a harmonia 
na joint-venture.Na figura 3 está exposto um resumo dos resultados obtidos nas entrevistas com os gestores de cada joint-venture, referentes aos aspectos estratégicos e relacionais observados nesta pesquisa empírica.

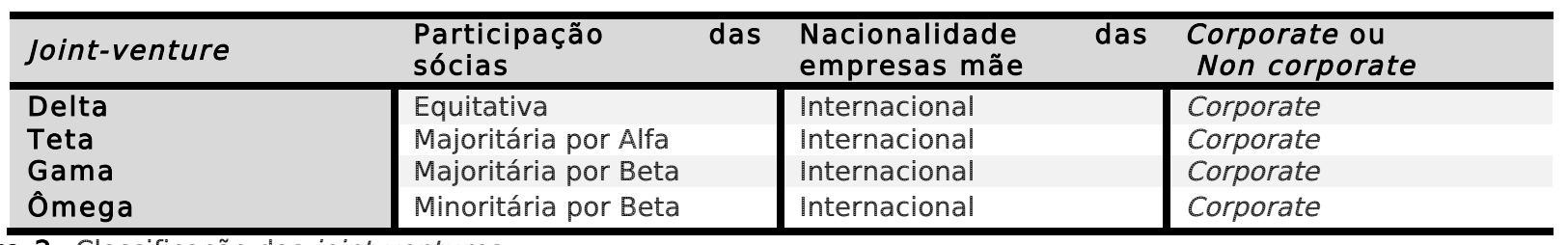

Figura 2. Classificação das joint-ventures

Fonte: elaborado pelos autores.

É possível perceber que as intenções estratégicas de cada uma das subsidiárias nacionais, em relação à formação da joint-venture, são distintas. Para Alfa, é uma oportunidade de trazer para seu mercado de atuação os conhecimentos que não são de seu domínio, como forma também de verticalização, sendo que as jointventures formadas por Alfa têm como principal cliente a própria Alfa, além de fornecer para as demais montadoras de veículos pesados localizadas nas regiões, em que é permitido o fornecimento conforme restrições mercadológicas contratuais. Para Beta, a intenção estratégica das joint-ventures reside em adentrar mercados estrangeiros, formando alianças com fornecedores estratégicos já instalados nos países alvos, facilitando sua penetração no mercado.

As vantagens, em geral, obtidas pelas joint-ventures giram em torno da conquista de mercado, expansão do negócio e consolidação da marca. As desvantagens são, basicamente, restrições mercadológicas impostas pelas sócias. Por outro lado, a fidelidade aos requisitos contratuais e a compatibilidade entre os sócios auxiliam as joint-ventures a prosperarem (Minervini, 1997; Keegan \& Green, 1999; Elmuti\&Kathawala, 2001 ).

Nas quatro joint-ventures pesquisadas, foi possível observar que os resultados inicialmente previstos na formação da aliança foram atingidos e até mesmo superados. Com isso, as empresas cresceram, ampliaram sua produção e melhoraram sua estrutura podendo atender o mercado previsto e até ampliar sua área de atuação. Estes resultados estão de acordo com a teoria apresentada por Kotler (2000), Kotabe e Helsen (2000), Das e Teng (2001) e Inpken (2006) ao mostrarem as vantagens obtidas nas formações de joint-ventures.

\begin{tabular}{|c|c|c|c|c|c|c|c|c|c|}
\hline \multirow{2}{*}{ 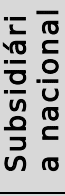 } & \multirow{2}{*}{ 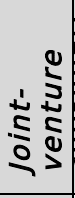 } & \multirow{2}{*}{ 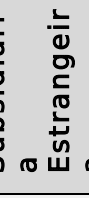 } & \multirow{2}{*}{ 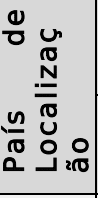 } & \multicolumn{4}{|c|}{ Aspectos Estratégicos } & \multicolumn{2}{|c|}{ Aspectos Relacionais } \\
\hline & & & & $\begin{array}{l}\text { Intençáo } \\
\text { da joint- } \\
\text { venture }\end{array}$ & Vantagens & $\begin{array}{l}\text { Desvanta- } \\
\text { gens }\end{array}$ & $\begin{array}{l}\text { Resultado } \\
\text { da joint- } \\
\text { venture }\end{array}$ & Dificuldades & Benefícios \\
\hline \multirow[b]{2}{*}{$\frac{\pi}{4}$} & $\stackrel{\text { Dே }}{\stackrel{ \pm}{0}}$ & 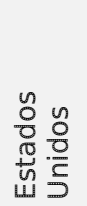 & $\overline{\bar{n}}$ & $\begin{array}{l}\text { Adquirir } \\
\text { know-how } \\
\text { e } \\
\text { tecnologia }\end{array}$ & $\begin{array}{l}\text { Aumento da } \\
\text { competitivi- } \\
\text { dade da } \\
\text { empresa e } \\
\text { ganho de } \\
\text { mercado. }\end{array}$ & $\begin{array}{l}\text { Restrições } \\
\text { mercadoló- } \\
\text { gicas } \\
\text { contratuais. }\end{array}$ & $\begin{array}{l}\text { Liderança } \\
\text { no } \\
\text { mercado } \\
\text { nacional } \\
(60 \%)\end{array}$ & $\begin{array}{lr}\text { Decisões em } \\
\text { consenso e } \\
\text { definições } \\
\text { contratuais } \\
\text { anulam } \\
\text { dificuldades. }\end{array}$ & $\begin{array}{l}\text { Problemas } \\
\text { culturais não } \\
\text { relatados }\end{array}$ \\
\hline & $\stackrel{\mathbb{2}}{\stackrel{0}{1}}$ & 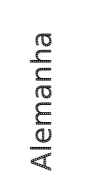 & $\begin{array}{l}\overline{\bar{n}} \\
\frac{0}{\infty} \\
\bar{\infty}\end{array}$ & $\begin{array}{l}\text { Adquirir } \\
\text { know-how } \\
\text { e } \\
\text { tecnologia }\end{array}$ & $\begin{array}{l}\text { Mercado em } \\
\text { expansão e } \\
\text { sem } \\
\text { concorrência } \\
\text { substancial }\end{array}$ & $\begin{array}{l}\text { Restrições } \\
\text { mercadoló- } \\
\text { gicas } \\
\text { contratuais. }\end{array}$ & $\begin{array}{l}\text { Liderança } \\
\text { no } \\
\text { mercado } \\
\text { nacional } \\
(90 \%)\end{array}$ & $\begin{array}{l}\text { Não } \\
\text { observadas. }\end{array}$ & $\begin{array}{l}\text { Respeito } \\
\text { mútuo fazem } \\
\text { as diferenças } \\
\text { culturais } \\
\text { agregarem }\end{array}$ \\
\hline \multirow[b]{2}{*}{ 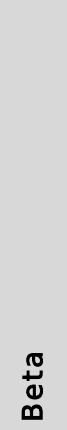 } & 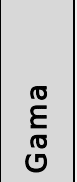 & 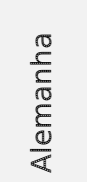 & 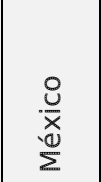 & $\begin{array}{l}\text { Expansão } \\
\text { de } \\
\text { mercado } \\
\text { para o } \\
\text { exterior }\end{array}$ & $\begin{array}{ll}\text { Forte } & \\
\text { reconheci- } & \\
\text { mento } & \text { da } \\
\text { marca } & \text { no } \\
\text { exterior } & \end{array}$ & $\begin{array}{l}\text { Restrições } \\
\text { mercadoló- } \\
\text { gicas } \\
\text { contratuais }\end{array}$ & $\begin{array}{l}\text { Expansão } \\
\text { no } \\
\text { mercado } \\
\text { estran- } \\
\text { geiro. }\end{array}$ & $\begin{array}{l}\text { Diferenças } \\
\text { culturais entre } \\
\text { as sócias } \\
\text { tiveram que ser } \\
\text { trabalhadas. }\end{array}$ & $\begin{array}{l}\text { Beta detém o } \\
\text { gerencia- } \\
\text { mento de } \\
\text { Gama por ser } \\
\text { majoritária }\end{array}$ \\
\hline & 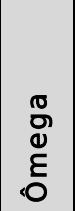 & 욤 & 음 & $\begin{array}{l}\text { Expansão } \\
\text { de } \\
\text { mercado } \\
\text { para o } \\
\text { exterior }\end{array}$ & $\begin{array}{l}\text { Sócia egípcia } \\
\text { influente no } \\
\text { local. } \\
\text { Incentivos } \\
\text { governamen- } \\
\text { tais }\end{array}$ & $\begin{array}{l}\text { Proteção da } \\
\text { economia } \\
\text { para produtos } \\
\text { concorrente } \\
\text { da produção } \\
\text { local }\end{array}$ & $\begin{array}{l}\text { Expansão } \\
\text { no } \\
\text { mercado } \\
\text { estran- } \\
\text { geiro }\end{array}$ & $\begin{array}{l}\text { Aspectos } \\
\text { culturais } \\
\text { religiosos } \\
\text { marcantes. } \\
\text { Instabilidade } \\
\text { política local. }\end{array}$ & $\begin{array}{l}\text { Respeito } \\
\text { cultura } \\
\text { religião }\end{array}$ \\
\hline
\end{tabular}

Figura 3. Resumo dos resultados observados

Fonte: elaborado pelos autores. 
Em relação às dificuldades encontradas na teoria (Keegan \& Green, 1999; Kotabe\&Helsen, 2000; Baker \&Gibbons; Murphy, 2002; Hsieh, Rodrigues \&Child, 2010) não foram detectadas por este estudo. Sendo que as dificuldades geradas pelas diferentes culturas que atuam em uma aliança, não se apresentaram significativas de modo a afetar o negócio por terem sido feitos estudos e análises da cultura local e implementadas as adaptações necessárias. Neste quesito, desperta a atenção o caso da empresa Teta, na qual as diferenças culturais foram percebidas como fator positivo que agregou valor a forma de gerenciar à joint-venture, e o caso Ômega, devido a cultura muçulmana e a instabilidade política onde, apesar das empresas realizarem um aprofundado estudo de viabilidade e mapeamento de todos os requisitos indispensáveis ao sucesso de cada operação, variáveis incontroláveis surgiram, tardando e comprometendo os resultados desta aliança como um todo.

Alianças com parceiros de forte presença em seus mercados, consistentes em suas decisões e planejamento e ainda, se possível, líderes nos seus segmentos de atuação, minimizam o impacto destas incertezas e mantém a estabilidade da joint-venture até o momento da retomada da situação normal. Estes riscos estão de acordo com a teoria exposta por Jeannet e Hennessey (1998).

Verificou-se, em todos os casos, esforços das subsidiárias em implementar as melhores práticas de cada uma das partes, e uma característica comum a todos os casos estudados é a adaptação dos procedimentos à cultura do local de instalação das fábricas, fator chave para o sucesso das joint-ventures, corroborando com o embasamento teórico de Minervini (1997), Keegan e Green (1999), Elmuti e Kathawala, 2001.

\section{Considerações Finais}

O objetivo deste estudo foi analisar a formação de joint-ventures de dois fabricantes da indústria automobilística, compreendendo aspectos estratégicos e relacionais destas alianças. Tendo o objetivo geral, foram propostos os seguintes objetivos específicos: verificar a intenção estratégica da formação da jointventure em cada um dos fabricantes; comparar as vantagens e desvantagens da aliança estratégica, assim como os benefícios e dificuldades; analisar os aspectos culturais e relacionais envolvidos.

Quanto à intenção estratégica da formação da joint-venture, percebe-se que as contribuições de Lorange\& Ross (1996) e Koza\& Lewis (1998) foram importantes no que tange ao aumento do nível de confiança entre as empresas envolvidas, riscos e incertezas e nível de controle, tendo em vista o longo prazo da relação. Lewis (1994) corrobora com os resultados encontrados quando enfatiza que o fortalecimento da aliança estratégica é diretamente proporcional ao aumento do nível de cooperação entre as partes. Sendo assim, devese destacar a necessidade de maior transferência de tecnologia, divisão dos custos e riscos e compartilhamento de recursos para a formação da joint-venture.

No entanto, uma das dificuldades encontradas foi a possibilidade das partes interessadas agirem em benefício próprio (individual) em relação à formação da joint-venture. Este fato foi observado nos estudos de Williamson (1996), Park \&Ungson, (1997), Chen, Peng\&Saparito (2002), Richey\& Morgan (2010) e Silva \& Brito (2013), onde se percebeu que o comportamento oportunista é considerado um entrave à formação da aliança estratégia, podendo contribuir para a limitação ou rompimento da parceria. Outras restrições quanto à formação de joint-ventures foram identificadas nos estudos de Keegan \& Green (1999), Kotabe\&Helsen (2000), Das \&Teng (2001), Baker, Gibbons\& Murphy (2002) e Hsieh, Rodrigues \&Child (2010), como por exemplo: resolução de conflitos, expansão da aliança, tempo de vida da parceria, governança estática e relacional e risco da parceria local. Nestes aspectos estão também inclusos as restrições mercadológicas, normalmente acordadas nos contratos das joint-ventures e que limitam a expansão da empresa. Estes elementos contribuíram para melhor percepção das lacunas relacionadas à formação de joint-ventures, tendo sido essenciais para construção desta pesquisa.

Algumas vantagens, apresentadas neste artigo, corroboram com as contribuições teóricas identificadas nos estudos de Kotabe\&Helsen (2000), Das \&Teng (2001), Lou (2002) e Inpken (2006), tais como: necessidade de aumento do nível de cooperação e desempenho entre as empresas, maior participação de mercado, redução de custos, inserção de produtos em novos mercados, acesso a novos canais de distribuição, redução de custos, transferência de tecnologia dentre outras.

Um dos motivadores para o desenvolvimento desta pesquisa foi a influência do aspecto cultural para a formação da joint-venture. Os estudos de Park \&Ungson (1997) e Steensmaet al. (1999) foram determinantes para a melhor compreensão deste aspecto. Sendo assim, percebeu-se que as diferentes culturas, provenientes dos países que compõem as empresas envolvidas na joint-ventures, são um limitador para a expansão e aprofundamento das relações interfirmas.

Outro aspecto identificado na pesquisa foi o relacional. A partir dos estudos de Das \&Teng (1996) e Sutcliffe\&Zaheer (1998) percebeu-se que as incertezas relacionais e tecnológicas interferem na formação de joint-ventures, sendo necessário o envolvimento das partes na busca pela inovação, maior cooperação entre as empresas envolvidas e troca de informação no intuito de minimizar os riscos interorganizacionais.

Outros achados da pesquisa dizem respeito a maior reflexão quanto a localização geográfica, escopo do produto, custos de transação e formas de controle (além da diferença cultural e aspectos relacionais já mencionados anteriormente). Estes elementos necessitam de melhor percepção antes da formação da joint- 
venture, tendo em vista o estabelecimento dos direcionadores estratégicos entre as organizações envolvidas. Os estudos de Peng\&Delios (2006), Li et al. (2010), Gulati (1995), Poppo\&Zenger (2002) e Jones, Hesterly\&Borgatti (1997) corroboraram para a obtenção de evidências empíricas a este respeito.

Para obter êxito, conforme foi possível observar ao longo das entrevistas semi-estruturadas, é recomendado que a proposta de aliança passe por um estudo de viabilidade detalhado, abrangendo, além dos aspectos mercadológicos, todos os aspectos culturais e relacionais envolvidos. Estes aspectos foram obtidos por meio das contribuições teóricas dos estudos deMinervini (1997), Keegan \& Green (1999), Elmuti\&Kathawala (2001) ao abordarem os fatores que podem levar uma joint-venture ao insucesso.

Como limitação do método utilizado na pesquisa, os resultados descritos não podem ser generalizados. Além disso, as entrevistas abrangeram apenas um entrevistado em cada joint-venture, não permitindo confrontar informações dentro da mesma organização. Esta pesquisa não apresenta contribuições teóricas para o tema de alianças estratégicas, sendo que sua proposta é de cunho empírico.

As contribuições deste estudo estão relacionadas à melhor compreensão da formação de joint-ventures, não tratando apenas das convencionais vantagens e desvantagens, mas abordando também as questões estratégicas e relacionais envolvidas e introduzindo uma série de oportunidades de pesquisas futuras: (i) a realização de uma pesquisa do tipo surveye com um amostra adequada de empresas para permitir a generalização dos resultados e a verificação de tendências na formação de joint-ventures na região, (ii) replicação desta mesma pesquisa com foco na formação de outro tipo de aliança estratégica, (iii) replicação desta pesquisa em outra região do país ou outro setor industrial, permitindo uma melhor percepção quanto aos resultados obtidos neste artigo, (iv) elaboração de estudos na fase pós-formação da joint-venture (por exemplo, estágio de recisão da parceria), (v) análise da formação de joint-venture com duração pré-determinada no contrato de formação, (vi) verificar a influência da formação da joint-venture no desempenho das organizações, analisando se o mesmo desempenho poderia ser obtido sem a formação da mesma.

\section{Notas}

Os autores agradecem as sugestões e recomendações realizadas pelos avaliadores, as quais foram centrais para qualificação deste estudo.

\section{Referências}

Baker, G., Gibbons, R. \& Murphy, K. (2003). Relational contracts in strategic alliances. Cambridge: MIT, Sloan School of Management. Disponívelem http://www.nber.org/books_in_progress/stragalli/baker.pdf.Acessadoem 25 jul 2013.

Bardin, Laurence. (2004). Análise de conteúdo. 3. ed. Lisboa: Edições 70.

Basso, M. (1994). Joint-venture: manual prático. Porto Alegre: Livraria do Advogado.

Bernardi, F. C. (2011) Estruturação e desenvolvimento de uma joint venture em busca de maior competitividade: o caso de uma empresa gaúcha do setor metal-mecânico. (Dissertação de Mestrado). Programa de Pós-Graduação em Administração, Universidade de Caxias do Sul, Caxias do Sul, Brasil.

Boone, L. E., \& Kurtz, D. L. Marketing contemporâneo. São Paulo: Cengage Learning.

Callahan, J., \& Mackenzie, S. (1999). Metrics for strategic alliance control. $R$ \& D Management, 24(4), p 365-377.

Chen, C. C., Peng, M. W. \&Saparito, P. A. (2002). Individualism, collectivism, and opportunism: a cultural perspective on transaction cost economics. Journalof Management, 28(4), 567-583.

Chesnais, J. F. (1996). A Mundialização do capital. São Paulo: Xamã.

Chopra, S., \&Meintl, P. (2001). Gestão da Cadeia de Suprimentos:Estratégia, Planejamento e Operações. São Paulo: Pearson Prentice Hall.

Chung, C. C. \& Beamish, P. W. (2012). Multi-party internacional joint ventures: multiple post-formation change processes. Journal of word Business, 47(4), 648-663.

Clegg, R., Hardy, C., \& Nord, W. (Orgs.). (1998). Handbook de estudosorganizacionais: modelos de análise e novas questões em estudos organizacionais. (Vol 1). São Paulo: Atlas.

Combs, J. G., \&Ketchen, D. J. (1999). Explaining interfirm cooperation and performance: toward a reconciliation of predictions from the resource-based view and organization economics. Strategic Management journal, 20 (9), 867-888.

Das, T. K., \&Teng, B. S. (2001) Trust, control and risk in strategic alliances: an integrated framework. Organization Studies, 22(2), 251-283.

Das, T. K., \&Teng, B. S. (1996). Risk types and inter-firm alliance structures. Journal of Management Studies, $33(6), 827-843$. 
Dahab, S., Guimarães, F., \& Dantas, J. R. (1992, Setembro). Transferência de Tecnologia e Joint-ventures no Brasil. Anais do XVI Encontro Anual da Associação Nacional dos Programas de Pós-Graduação em Administração. Canela, RS, Brasil.

Deitz, G. D., Tokman, M., Richey, G., \& Morgan, R. M. (2010).Joint venture stability and cooperation: Direct, indirect and contingent effects of resource complementarity and trust. Industrial Marketing Management, 39(5), 862-873.

Doh, J.P. (2005). Offshore outsourcing: implications for international business and strategic management theory and practice. Journal of Management Studies, 42(3), 695-704.

Doz, Y. L., \& Hamel, G. (1998). Alliance advantage: The art of creating value through partnering. Boston: Harvard Business School Press.

Elmuti, D. \&Kathawala, Y. (2001). An overview of strategic alliances, Management Decision, $39(3), 205$ - 218.

Faems, D., Looy, B., ;Janssens, M., \&Vlaar, P. (2012) The process of value realization in asymmetric new venture development alliances: Governing the transition from exploration to exploitation. Journal of Engineering and Technology Management, 29(4), 508-527.

Flick, Uwe.(2009). Introdução à pesquisaqualitativa.(3a. ed.) Porto Alegre: Artmed.

Gibbs, G. (2009). Análise de dados qualitativos. Porto Alegre: Bookman.

Gulati, R. (1995). Social structure and alliance formation patterns: a longitudinal analysis. Administrative Science Quarterly. Ann Arbor, 40, 619-652.

Gulati, R. (1998). Alliances and Networks.Strategic Management Journal, 19, 293 - 317.

Gulati, R., Nohrian, N, \&Zaheer.(2000). A. Strategic netwoks.Strategic Management Journal, 21(3), 203-215.

Hätönen, J. (2009). Making the locational choice: a case approach to the development of a theory of offshore outsourcing and internationalization. Journal of International Managemen, 15(1), 61-76.

Hsieh, L. H. Y., Rodrigues, S. B., \& Child, J. (2010). Risk perception and post-formation governance in international joint venture in Taiwan: the perspective of the foreign partner. Journal of International Management, 16(3), 288-303.

Hoskisson, R. E., Hitt, M. A., Ireland, R. D., \& Harrison, J. S. (2009). Estratégia Competitiva. São Paulo: Cengage Learning.

Inpken, A. Strategic alliances. In: Hitt, M., Freeman, R. E., \&Harrisson, J. S. (Edit). (2006). Theblackwe/l handbook of strategic management, (2a. ed.), 409-432.

Jeannet, J. P., \& Henessey, H. D. (2001). Global Marketing Strategies. (4th ed), Boston: Houghton Mifflin Company.

Jiang, M. S., Chu, R., \& Pan, Yigang. (2011). Anticipated duration of international joint venture: a transaction cost perspective. Journal of Internacional Management, 17(2), 175-183.

Jones, C., Hesterly, W. S., \& Borgatti, S. P. (1997). A general theory of network governance: Exchange conditions and social mechanisms. The Academy of Management Review, 22(4), 911-945.

Keegan, W.J., \& Green, M.C. (1999). Princípios de Marketing Global. São Paulo: Saraiva.

Klotzle, M. C. (2002). Alianças estratégicas: conceito e teoria. Revista de Administração Contemporânea (RAC), 6(1), 85-104.

Kogut, B., \& Zander, U. (1992).Knowledge of the Firm, Combinative Capabilities, and the Replication of Technology. Organization Science, 3(3), 383-397.

Kotabe, M., \&Helsen, K. (2000). Administração de Marketing Global. São Paulo: Atlas.

Kotler, P. (2000). Administração de Marketing: a edição do novo milênio. (10ª ed.). São Paulo: Prentice Hall. Koza, M. P., \& Lewis, A. Y. (1998). Co-evolution of strategic alliances. Organization Science, 9(3), $255-264$.

Kumar, M. V. S. (2007). Asymmetric Wealth Gains in Joint Ventures: Theory and Evidence. Finance Research Letters, 4(1), 19-27.

Lewis, Jordan. (1994). Alianças estratégicas. São Paulo: Pioneira.

Li, Y., Xie, E., Teo, H. \& Peng, M. W. (2010). Formal control and social in domestic and internacional buyersupplier relationships.JournalofOperations Management, 28 (4), 333-344.

Lorange, P., \& Ross, J. (1996). Aliança Estratégica: formação, implementação e evolução. São Paulo: Altas. 
Aspectos estratégicos e relacionais das alianças do tipo joint-venture: o caso de dois fabricantes da indústria automobilística

Lou, Y. (2002). Contract, cooperation, and performance in international joint ventures. Strategic Management Journal, 23, 903-919.

Minervini, N. (2005). O Exportador. (4ae ed). São Paulo: Prentice Hall.

Mintzberg, H.; Ahlstrand, B., \& Lampel, J. (2000). Safári de estratégia: um roteiro pela selva do planejamento estratégico. Porto Alegre: Bookman.

Nielsen, B. B. (2009). Strategic fit, contractual, and procedural governance in alliances. Journalof Business Research, 46(1), 682-689.

Noleto, M. J. (2000). Parcerias e alianças estratégicas: uma abordagem prática. São Paulo: Global.

Ohno, Taiichi. (1997). O sistema Toyota de Produção: além da produção em larga escala. Porto Alegre: Bookman.

Oliver, A. L. \& Ebers, M. (1998). Networking network studies: and analysis of conceptual configurations in the study of inter-organizational relationships. Organization Studies, 19 (4), 549-583.

Oliver, C. (1990). Determinants of interorganizational relationships: integration and future directions. Academy of Management Review, 15(2), 241-265.

Park, S. H., \& Ungson, G. R. (1997). The effect of national culture, organizational complementarity, and economic motivation on joint venture dissolution. Academy of Management journal, 40(2), 279-307.

Pearce, R. J. (1997). Toward understanding venture performance and survival: a bargaining and influence approach to transaction cost theory. Academy of Management Review, 22 (1), 203-225.

Peng, M. W. (2000). Business strategies in transition economies. Thousand Oaks, CA: Sage.

Peng, M. W. (2002). Cultures, institutions, and strategic choices: Towards an institution-based view of business strategy. In Gannon, M. \& Newman, K. (Eds.), Handbook of cross-cultural management. Oxford, UK: Blackwell.

Peng, M. W. (2008). Estratégia global. São Paulo: Thomson Learning.

Peng, M. W. \& Delios, A. (2006). What determines the scope of the firm over time and around the world? An Asia Pacific perspective.Asia Pacific Journal Manage, 23, 385-405.

Poppo, L. \& Zenger, T. (2002). Do formal contracts and relational governance function as substitutes or complements? Strategic Management Journal, 23, 707-725.

Porter, M. E. (1980). Estratégia competitiva: técnicas para a análise de indústrias e da concorrência. (7’̣a. ed.) Rio de Janeiro: Campus.

Porter, M. E. (1990). Vantagem competitiva: criando e sustentando um desempenho superior. Rio de Janeiro: Campus.

Richards, M., \& Indro, D. C. (2006). Government as an alliance partner. In: Ariño, A., \& Reuer, J. J. Strategic alliances: governance and contractes. Palgrave: Macmillan, 11-20.

Richardson, R. J. (1999). Pesquisa social: métodos e técnicas. (3a. ed.), São Paulo: Atlas.

Rod, M. (2009). A model for the effective management of joint-ventures: A case study approach. Internationaljournalof Management, 26(1), 3-17.

Rodrigues, S. B. (1999). Formação de alianças estratégicas em países emergentes: o caso Brasil-China. In: Rodrigues, S. B. (org.). Competitividade, alianças estratégicas e gerências internacional. São Paulo: Atlas, 183205.

Silva, A. A., \& Brito, E. P. Z. (2013). Incerteza, racionalidade limitada e comportamento oportunista: um estudo na indústria brasileira. Revista de Administração da Mackenzie - RAM, 14(1), 176-201.

Steensma, H. K., Marino, L., Weaver, K. M., \& Dickson, P. H. (1999). The influence of national culture on the formation of technology alliances by entrepreneurial firms.Academy of Management journal, 43(5), 951-973.

Sutcliffe, K. M. \& Zaheer, A. (1998). Uncertainty in the transaction environment: an empirical test. Strategic Management Journal, 19, 1-23.

Tondolo, V. A. G. \& Puffal, D. P. (2010). Antecedentes e resultados de um projeto de capacidade de fornecedores sob a ótica das relações interorganizacionais. Revista Alcance - Eletrônica, 17 (1), 84-97.

Tsang, E. W. K. (2000). Transaction Cost and Resource-Based Explanations of Joint Ventures: A Comparison and Synthesis. Organizationstudies, 21(1), 215-242.

Van de Ven, A. H., Angle, H. L. \& Poole, M. S. (1989). Research on the Management of Innovation: the Missesota studies. New York: Harper \&Row.

Vergara, Sylvia Constant. (2006). Projetos e relatórios de pesquisa em administração. (7ạ. ed.), São Paulo: Atlas. 
Marina D'Agostini, Rodrigo Marques de Almeida Guerra, Rosa Maria Sartor, Vilmar Antonio Gonçalves Tondolo

Verschoore, J. R. \& Balestrin, A. (2008). Fatores relevantes para o estabelecimento de redes de cooperação entre empresas do Rio Grande do Sul. Revista de AdministraçãoContemporânea (RAC), 12, 1043-1069.

Williamson, O. E. (1996). The mechanisms of governance. Oxford: Oxford University Press.

Yin, Robert K. (2005). Estudo de caso: planejamento e métodos. (3a. ed.), Porto Alegre: Bookman. 


\section{APÊNDICE A \\ Roteiro de entrevista sobre Aliança Estratégica na Indústria Automotiva da Serra Gaúcha}

1. Conte um pouco da história da empresa e como ocorreu a joint-venture.

2. Quais as razões estratégicas que levaram à formação da joint-venture?

3. Qual a participação de cada uma das empresas? A participação tendência a maneira de gerenciar cada empresa?

4. Quais as vantagens ou ganhos reais obtidos?

5. Quais as dificuldades encontradas?

6. As barreiras culturais afetaram positiva ou negativamente esta formação? Como isto ocorreu?

7. As alianças atuais influenciaram ou poderão vir a influenciar novas alianças estratégicas? De que forma?

8. Existem restrições mercadológicas estabelecidas por estas alianças? Isto tem afetado a conquista de novos mercados e expansão do negócio?

9. Como os concorrentes reagiram a estas alianças?

10. De uma maneira geral, a joint-venture contribuiu para o sucesso da empresa? Os mesmos resultados poderiam ter sido atingidos sem ela? Justifique. 